\title{
Molecular Phylogeography of the Endemic Five-lined Skink (Plestiodon marginatus) (Reptilia: Scincidae) of the Ryukyu Archipelago, Japan, with Special Reference to the Relationship of a Northern Tokara Population ${ }^{1}$
}

\author{
Masanao Honda, ${ }^{2}$ Taku Okamoto, ${ }^{3}$ Tsutomu Hikida, ${ }^{3}$ and Hidetoshi Ota ${ }^{4,5}$
}

\begin{abstract}
Phylogenetic relationships were inferred for populations of the Ryukyu five-lined skink Plestiodon marginatus, a species showing an extraordinary distribution across the Tokara Tectonic Strait. Phylogenetic analyses of 809 base positions of the mitochondrial $12 \mathrm{~S}$ and $16 \mathrm{~S}$ rRNA genes supported collective divergence of the southern Tokara and northern Amami populations, which have been classified as P. m. oshimensis. A population from Nakanoshima, an island of the Tokara Group north of the Tokara Tectonic Strait, has the closest affinity with the Okinawajima population of $P$. m. marginatus rather than with the geographically closer southern Tokara and northern Amami populations. This result is concordant with that of a recent allozyme study and suggests an origin of the Nakanoshima population through long-distance dispersal from the Okinawa Island Group. Also, our results strongly suggest a closer relationship of a population of $P$. m. oshimensis from Okinoerabujima, a southern island of the Amami Group, with P. m. marginatus from Okinawajima than with the "consubspecific" southern Tokara and northern Amami populations. Both Nakanoshima and Okinoerabujima populations are usually referred to as P. m. oshimensis, and therefore our results indicate nonmonophyly of $P$. m. oshimensis in the current taxonomic arrangement.
\end{abstract}

The scincid lizards of the genus Plestiodon Duméril \& Bibron, 1839 (formerly referred to as Eumeces Wiegmann, 1834 [Brandley et

${ }^{1}$ This study was funded in part by a Grant from the 21st Century Center of Excellence (COE) Program entitled "The Comprehensive Analyses on Biodiversity in Coral Reef and Island Ecosystems in Asian and Pacific Regions" to the University of the Ryukyus, and also by Grants-in-Aid (Young Scientists B-16710168 to M.H. and C-18570090 to H.O.), all from the Japan Ministry of Education, Culture, Sports, Science, and Technology (Monbu-kagaku-sho). Manuscript accepted 2 September 2007.

${ }^{2}$ Faculty of Education, University of the Ryukyus, Nishihara, Okinawa 903-0213, Japan.

${ }^{3}$ Department of Zoology, Graduate School of Science, Kyoto University, Sakyo, Kyoto 606-8502, Japan.

${ }^{4}$ Tropical Biosphere Research Center, University of the Ryukyus, Nishihara, Okinawa 903-0213, Japan. .ac.jp).

${ }_{5}^{5}$ Corresponding author (e-mail: ota@sci.u-ryukyu

Pacific Science (2008), vol. 62, no. 3:351-362

(C) 2008 by University of Hawai'i Press

All rights reserved al. 2005, Smith 2005]) show a broad distribution in temperate and subtropical areas of both the Old and New Worlds. From the insular region of East Asia, eight species and two subspecies of the genus are recognized, of which the following six species and one subspecies are assigned to the latiscutatus species-group: P. latiscutatus from Izu Peninsula and the Izu Islands (formerly referred to as $P$. okadae [see Motokawa and Hikida (2003) for details on the recent change in specific name]); P. japonicus from the Osumi Group of the northern Ryukyus and the main islands of Japan exclusive of Izu Peninsula (formerly referred to as $P$. latiscutatus [see Motokawa and Hikida (2003)]); P. marginatus oshimensis from the Tokara and Amami Groups of the northern and central Ryukyus; P. m. marginatus from the Okinawa Group of the central Ryukyus; P. barbouri from the Amami and Okinawa Groups; P. stimpsonii from the Yaeyama Group of the southern Ryukyus; and P. elegans from the Senkaku Group, Taiwan, and eastern continental China (Hikida 1993, 2002). Of these, P. japonicus and P. mar- 
ginatus were initially considered to have been separated geographically by the Tokara Tectonic Strait, which is located in the Tokara Group between Akusekijima and Kojima or Kodakarajima. The Tokara Tectonic Strait is thought to have persisted for more than 2 million years since its initial formation at the river mouth of ancient Huang-he (i.e., Yellow River [Kizaki and Oshiro 1977, 1980]), and many lineages of terrestrial animals, such as newts of the genus Cynops and lizards of the genus Takydromus, show a distinct genetic break around this strait (e.g., Hayashi and Matsui 1988, Ota et al. 2002). Populations of Plestiodon on islands north of the Tokara Tectonic Strait (henceforth referred to as the northern Tokara islands) had been assigned to $P$. japonicus, whereas those found on islands south of the Tokara Tectonic Strait (southern Tokara islands) were assigned to P. marginatus (Figure 1) on the basis of a few external characters, such as the presence of the postnasal scale at substantial frequency (P. japonicus) or its complete absence (P. marginatus) (e.g., Toyama 1989, Hikida et al. 1992, Ota et al. 1994).

Hikida et al. (1992) reported that specimens of putative $P$. japonicus from a few northern Tokara islands differ from those from the main islands of Japan in the number of midbody scale rows. They also noted remarkable differences in a few characters in the scutellation and coloration among the northern Tokara samples. Based on allozyme data, Motokawa and Hikida (2003) suggested that samples from three northern Tokara islands (Kuchinoshima, Nakanoshima, and Suwanosejima) are genetically closer to $P$. marginatus than to $P$. japonicus. A few recent authors, therefore, regard the northern Tokara populations as belonging to $P$. marginatus (Hikida 2002, Ota 2003).

However, this view is not much supported from the morphological taxonomy, and this is particularly true with the Nakanoshima population in which a substantial proportion of specimens so far examined had the postnasal scale (T.H. and H.O., unpubl. data). Moreover, detailed relationships of $P$. marginatus populations in Motokawa and Hikida's (2003) and other recent allozyme studies are not consistent with their geographic arrangement or with the latest subspecific classification of P. marginatus. For example, the Nakanoshima population, assigned to the subspecies $P$. $m$. oshimensis in the latest classification (Hikida 2002), was indicated to be closer to the nominotypical Okinawa Group populations than to the geographically much closer (Figure 1) southern Tokara and Amamioshima (type locality of P. m. oshimensis) populations (Motokawa and Hikida 2003). A population of Okinoerabujima (a southern island of the Amami Group), usually assigned to P. m. oshimensis on the basis of tail color pattern, was also shown to be closer to the nominotypical subspecies of the Okinawa Group than to the consubspecific populations of Amamioshima and adjacent islands (Kato et al. 1994, Motokawa et al. 2001).

Analysis of sequence variation in some mitochondrial DNA genes, such as those of $12 \mathrm{~S}$ and $16 \mathrm{~S}$ ribosomal RNA (rRNA), is known to be effective in estimating phylogenetic relationships among closely related species (e.g., Hedges et al. 1993, Reeder 1995, Honda et al. 2003, Okamoto et al. 2006). Also, it is known that in some reptilian taxa, such as geoemydid turtles, analyses of mitochondrial DNA sequences show substantial incongruence with those of allozyme data (e.g., see the results of Sites et al. [1984] versus those of Honda et al. [2002a,b] and Spinks et al. [2004]). However, no sequence data are available to verify the above-mentioned results of allozyme analyses on the geographic boundary between P. japonicus and P. marginatus, and on the validity of current subspecific classification of the latter.

To remedy this situation, we examined the phylogenetic relationships of representative populations of $P$. marginatus, $P$. japonicus, and other species of the latiscutatus speciesgroup by analyzing mitochondrial $12 \mathrm{~S}$ and $16 \mathrm{~S}$ rRNA genes. Our purposes were to assess the phylogenetic hypotheses proposed by Kato et al. (1994), Motokawa et al. (2001), and Motokawa and Hikida (2003), and to discuss historical biogeography and subspecific classification of P. marginatus. 


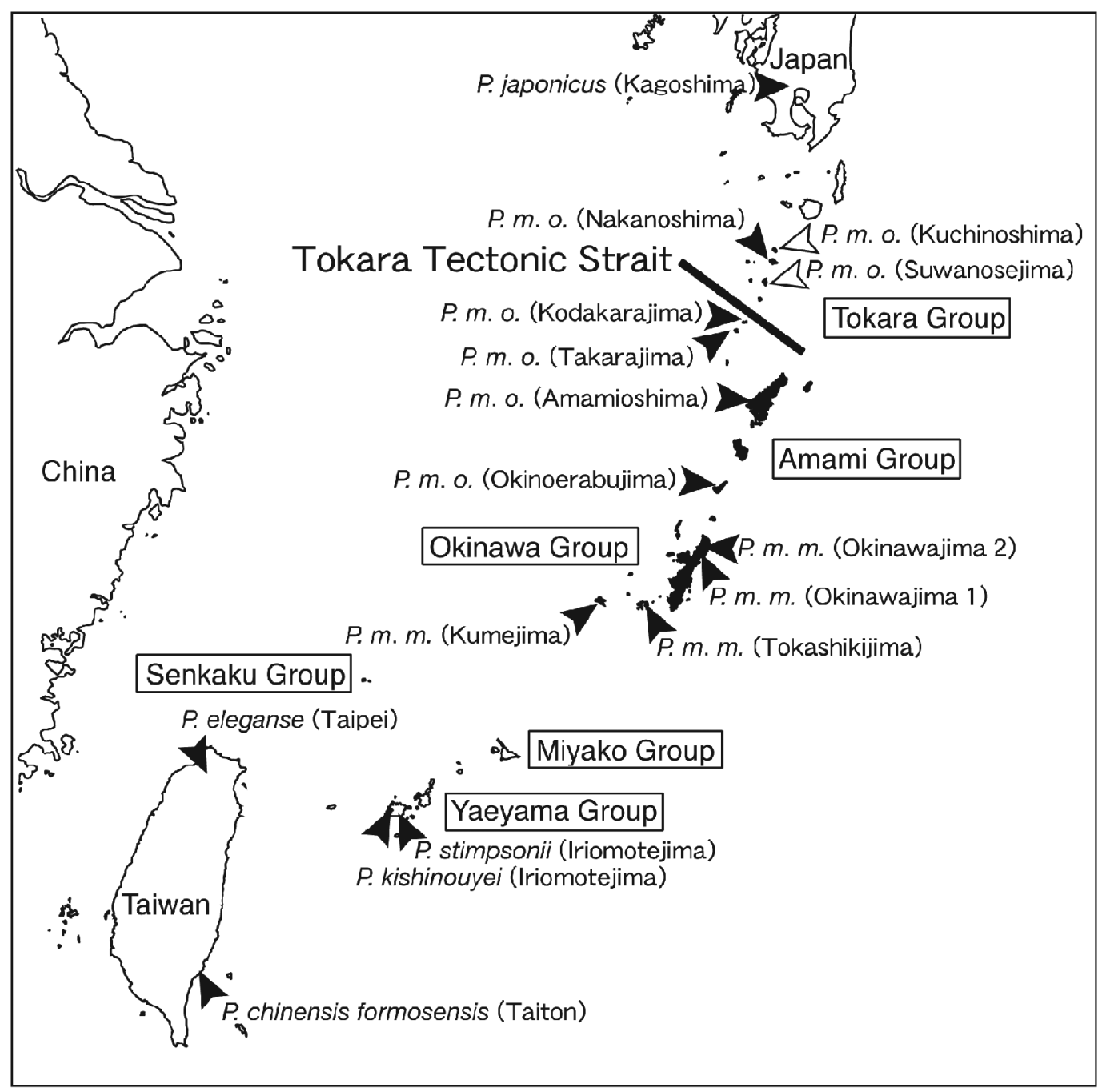

FIGURE 1. Map of the subtropical East Asian islands showing sampling localities of Plestiodon specimens used in this study (indicated with filled arrows). Islands where P. marginatus occurs are shaded, and those whose names are referred to in the text but without data for representative Plestiodon specimens are indicated with open arrows.

\section{MATERIALS AND METHODS}

Tissues were obtained from eight populations of Plestiodon marginatus and one population of P. japonicus (Figure 1 [see Appendix for details]). Single samples representing each of two other species of the latiscutatus speciesgroup ( $P$. stimpsonii and $P$. elegans) and two species of another species-group of Plestiodon (the chinensis species-group [Hikida 1993]) $(P$. kishinouyei and $P$. chinensis) were also examined (Figure 1). Besides these, we incorporated published sequence data for $P$. japonicus from another locality (Kyoto, the main island of Japan: AB028770 and AB028781), P. barbouri (DQ173515 and DQ173534), and $P$. egregius (AB016606).

Extraction, amplification, and sequencing 
procedures for DNA were described elsewhere (Honda et al. 1999a,b). Parts of the mitochondrial $12 \mathrm{~S}$ and $16 \mathrm{~S}$ rRNA genes, approximately 820 base pairs (bp) in total, were amplified by the polymerase chain reaction (PCR) using the following primers: L1091 and H1478 (Kocher et al. 1989) for $12 \mathrm{~S}$ rRNA, and L2206 and L2606 (Hedges et al. 1993) for 16S rRNA.

Alignments for DNA sequences were determined based on the maximum nucleotide similarity using CLUSTAL W 1.4 (Thompson et al. 1994). We then compared sequence alignments with different gap costs (penalty for each gap opening $=6,9$, or 12) to identify ambiguously aligned regions (Reeder 2003). The resultant alignments were identical with each other and involved seven insertions and deletions. Thus, we used sequence data for 809 sites for phylogenetic analyses, excluding these seven base positions.

To infer relationships among taxa, maximum-likelihood (ML) analysis was performed under the GTR+I+gamma model, which was selected in a series of hierarchical likelihood ratio tests using Modeltest 3.X (Posada and Crandall 1998). Unweighted maximum parsimony (MP) analysis was conducted using the heuristic search option with tree bisection-reconnection (TBR) branch swapping and 500 random taxon addition replicates. The neighbor-joining (NJ) method (Saitou and Nei 1987) was also applied on the basis of a pairwise matrix of distances from Kimura's (1980) two-parameter model. All these analyses were performed using PAUP ${ }^{*}$ 4.0b (Swofford 1998). Bayesian (BI) analysis was also conducted using MrBayes 3.12 (Ronquist and Huelsenbeck 2003) with the same best-fit model as selected in ML. Bayesian analyses were initiated from random starting trees and run for $1,000,000$ generations, sampling every 100 generations. The Markov chain was considered to have converged when stationarity was reached (Leaché and McGuire 2006). We thus tested for convergence by plotting the posterior probability values of nodes against generation time in a cumulative fashion using the online computer program AWTY (Wilgenbusch et al. 2004). Likelihood values stabilized by 100,000 gen- erations, and the first 100,000 generations were discarded as "burn-in."

Confidences of branches for NJ and MP analyses were assessed by 1,000 bootstrap resamplings (Felsenstein 1985). With respect to ML analysis, confidences were evaluated by only 100 bootstrap resamplings because of the computational limitation. The validity of nodes from BI was assessed by posterior probabilities (PPs) of 900,000 generations ( $=9,000$ trees). With respect to the interpretation of bootstrap proportions (BPs) and Bayesian PPs, we considered $\mathrm{BP} \geq 70 \%$ (Hillis and Bull 1993) or PP $\geq 0.95$ (Huelsenbeck and Rannala 2004) as significant evidence of monophyly.

The extent of mitochondrial DNA substitutions between taxa was used to estimate the date of their evolutionary divergence. A rate of $2.0 \%$ nucleotide substitution per million years (myr) was once broadly applied (e.g., Brown et al. 1982, Wilson et al. 1985, Avise 1994). Recently, however, an evolutionary rate of $0.65 \% / \mathrm{myr}$ has been used in estimating divergence time for the scincid lizards, as well as for iguanid, agamid, varanid, and gekkonid lizards, bufonid toads, salamandrid salamanders, and some fishes (Bermingham et al. 1997, Macey et al. 1998, 1999, Schulte et al. 2000, 2003, Weisrock et al. 2001, Honda et al. 2006). Because no fossil data were available for calibration specific to the subject under study, we tentatively applied $0.65 \% / \mathrm{myr}$ to our data. Resultant estimations of divergence time presented here may therefore be rather imprecise (Kumazawa and Nishida 2000), but we believe these still provide some meaningful insights into the historical biogeography of Plestiodon around the Ryukyu Archipelago.

\section{RESULTS}

The 12S rRNA fragment consisted of 385 aligned sites, of which 80 varied among taxa and 42 were parsimony informative. For $16 \mathrm{~S}$ rRNA, a total of 431 aligned sites was resolved, of which 75 were variable and 39 were parsimony informative. Within P. marginatus, interpopulational nucleotide replacements varied from 1 bp $(0.1 \%$ uncorrected 
"p" genetic distance: Takarajima versus Amamioshima; and Okinoerabujima versus one specimen from Okinawajima [Okinawajima 2]) to 23 bp (2.8\%: Kodakarajima versus Okinawajima 2; and Kodakarajima versus Tokashikijima). With respect to the Nakanoshima sample, the genetic divergence with either of the P. japonicus samples (3.4\%) was distinctly smaller than divergence with samples of $P$. marginatus $(0.2-2.7 \%$, mean $=1.4 \%)$, P. elegans $(2.3 \%)$, and P. stimpsonii (2.8\%). Of the P. marginatus examined, one specimen of the Okinawajima sample (Okinawajima 1) was almost indistinguishable genetically $(0.2 \%)$ from the Nakanoshima sample, whereas samples from geographically proximate islands, such as those from the southern Tokara islands and Amamioshima, were much more genetically dissimilar (2.2-2.7\%) to the latter. Likewise, the $\mathrm{p}$ distance of the Okinoerabujima sample, currently assigned to $P . m$. oshimensis, was much greater with other consubspecific samples from the southern Tokara islands and Amamioshima (2.0-2.7\%) than the $\mathrm{p}$ distance with $P$. m. marginatus samples from the Okinawa Group (0.1-1.4\%) (Table 1).

As such, the isolation period of the Nakanoshima population from $P$. japonicus was estimated to be $5.3 \mathrm{myr}$, whereas that of the former from $P$. marginatus varied from 0.4$0.6 \mathrm{myr}$ (versus the Okinawajima population) to $4.2 \mathrm{myr}$ (versus the Kodakarajima population). With respect to the Okinoerabujima population, the estimated isolation period showed a pattern similar to that in the Nakanoshima population, varying from $0.2-0.8$ myr (versus the Okinawajima population) to 4.2 myr (versus Kodakarajima) (Table 1).

The ML phylogeny derived from aligned sequence data is shown in Figure 2. Plestiodon marginatus is monophyletic, but poorly supported $(\mathrm{BP}<50 \%)$. Within P. marginatus, two distinct clades, each consisting of samples from two southern Tokara islands and Amamioshima ( $\mathrm{BP}=99 \%$ : node 1$)$, and of the Tokashikijima and Kumejima samples ( $\mathrm{BP}=71 \%$ : node 2 ), were recognized. Samples from Okinawajima, Nakanoshima, and Okinoerabujima were unified with each other (node 3 ) and then collectively with node 2.
However, support for these relationships is weak ( $\mathrm{BP}<70 \%)$. It is interesting that the two Okinawajima specimens are not each other's closest relatives, with one sample most closely related to the Nakanoshima sample (node 4) and the other to the Okinoerabujima sample (node 5): although neither of these relationships received substantial BP support $(\mathrm{BP}<70 \%)$.

Results of NJ and BI analyses (not shown) were consistent with the ML phylogeny, except for the existence of the TakarajimaAmamioshima cluster (99\%) in the NJ tree. Also, one of the four shortest trees of MP (not shown) was identical with the ML phylogeny in branching topology. In all these analyses, nodes 1 and 2 were strongly supported. Node 3 was highly supported in the $\mathrm{NJ}(\mathrm{BP}=92 \%)$ and Bayesian $(\mathrm{PP}=0.96)$ analyses. Validity of nodes 4 and 5 was significantly supported only in $\mathrm{NJ}$ analysis $(\mathrm{BP} \geq 70 \%)$.

\section{DISCUSSION}

Our results confirm assignment of the Nakanoshima population to $P$. marginatus rather than to $P$. japonicus. Moreover, our findings support Motokawa and Hikida's (2003) conclusion from allozyme data by placing the Nakanoshima sample with $P$. m. marginatus from the Okinawa Group rather than with $P$. $m$. oshimensis from Amamioshima and the southern Tokara islands, although statistical support to such relationships is weak.

We estimate that the Tokara Tectonic Strait, separating the northern Tokara islands (including Nakanoshima) from the central Ryukyus (consisting of the southern Tokara islands, and the Amami and Okinawa Groups [Figure 1]), dates back to no later than the Pliocene in formation (Kizaki and Oshiro 1977, 1980). Since then, the strait seems to have consistently been a barrier to the dispersal of a number of terrestrial animals, becoming one of the most distinct borders between the Oriental and Palearctic faunal realms (Kato 1989, Hikida et al. 1992, Ota 1998, 2000).

Several taxa, including the Ryukyu shortlegged skink (Ateuchosaurus pellopleurus), Ho- 


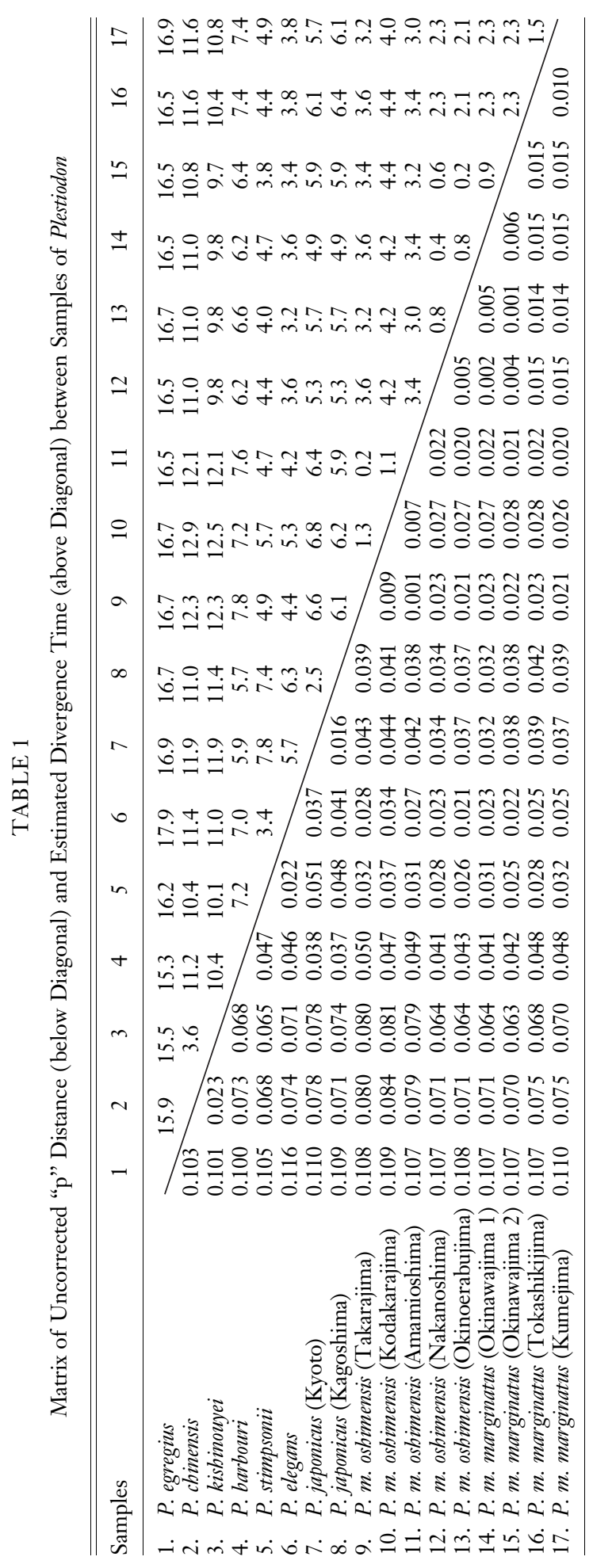




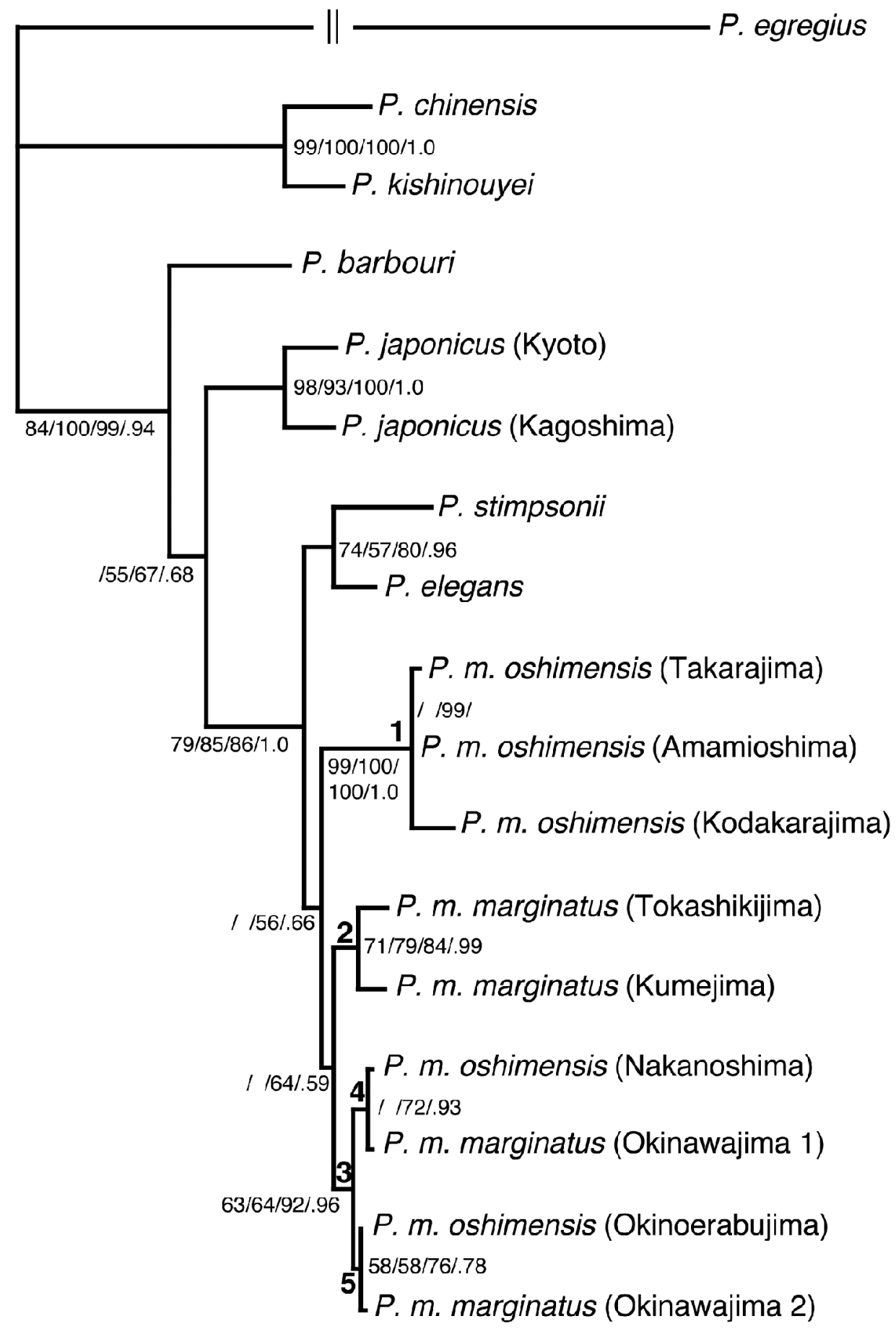

0.1

FIGURE 2. Maximum-likelihood (ML) phylogeny derived from 12S and 16S rRNA sequence data among populations of Plestiodon marginatus and related species (-Ln likelihood $=2,325.2)$. The first three numbers below each node are bootstrap proportions (BPs) of the 100; 1,000; and 1,000 replications in the ML, maximum parsimony (MP), and neighbor-joining (NJ) analyses, respectively. BP values smaller than $50 \%$ are omitted. The last number indicates the Bayesian posterior probability (PP). PP values smaller than 0.50 are also omitted. 
kou gecko (Gekko hokouensis), and the Ryukyu kajika frog (Buergeria japonica), inhabit both sides of the Tokara Tectonic Strait (Hikida et al. 1992, Ota et al. 1994). The occurrence of P. marginatus on Nakanoshima (i.e., the northeastern side of the strait), established by both allozyme and DNA data, is an additional example of this biogeographically exceptional distribution pattern in nonvolant terrestrial animals.

Populations of the short-legged skink, Hokou gecko, and kajika frog north of the Tokara Tectonic Strait have their closest relatives in islands immediately south of the strait (i.e., those in the southern Tokara islands, or Amamioshima and adjacent islands, or both) (Nishioka et al. 1987, Toda et al. 1997, 2001, Ota et al. 1999). This suggests that the northern populations have originated through short-distance oversea dispersals across the strait (Ota 1998). In contrast, the population of Plestiodon marginatus north of the Tokara Tectonic Strait (i.e., Nakanoshima) exhibits closer affinity with the Okinawajima population than with populations immediately south of the strait. Because the $\mathrm{p}$ distance between the former populations suggests that initiation of their isolation dates back to no earlier than the middle Pleistocene (i.e., long after formation of the Tokara Tectonic Strait), the current Nakanoshima population is likely to be a consequence of long-distance oversea dispersal from Okinawajima (Figure 1). Relationships revealed in this study also suggest that the frequent occurrence of the postnasal scale in the Nakanoshima population, unique within the highly supported stimpsonii-elegans-marginatus clade (Hikida 1993), is a consequence of independent derivation or retention of an ancestral character state rather than a synapomorph with $P$. japonicus.

With respect to the Okinoerabujima population, allozyme analyses demonstrated its closer relationship with populations of the nominotypical subspecies of the Okinawa Group including Kumejima than with those of P. m. oshimensis of the Amami Group and southern Tokara islands (Kato et al. 1994, Motokawa et al. 2001). Our results confirmed closer affinity of the Okinoerabujima population to the Okinawa Group populations and went even further to associate the former directly with the Okinawajima population by placing the Kumejima population externally (Figure 2). This further indicates that the distinct backward extension of body stripes onto the tail, by which the Okinoerabujima population was assigned to $P . m$. oshimensis together with other Amami Group and southern Tokara populations (Hikida 1996), is actually a consequence of independent derivation or of retention of an ancestral character state.

Our results strongly suggest that neither of the currently designated subspecies of $P$. marginatus is monophyletic. To minimize frequency in taxonomic changes, however, we defer revision of subspecific classification of $P$. marginatus to future studies using additional samples representing the other taxonomically crucial populations, such as those from Kuchinoshima and Suwanosejima of the northern Tokara islands, Tokunoshima and Yoronjima of the Amami Group, and isolated Iwotorishima (Kato et al. 1994, Motokawa et al. 2001, Motokawa and Hikida 2003). Further resolution of the process of divergence of $P$. marginatus and related taxa in the East Asian islands with substantial statistical support will also require sequence data for additional mitochondrial genes, as well as for some nuclear genes.

\section{ACKNOWLEDGMENTS}

We thank M. Toyama, J. Motokawa, M. Toda, and K. Daicho for helping and encouraging us throughout this project. Special thanks are due N. H. Kumazawa, T. Denda, N. Satoh, T. Nakabo, H. Nakamura, N. Hayashida, G. Taguchi, T. Negishi, and other members of the Tropical Biosphere Research Center and Center of Molecular Biosciences, University of the Ryukyus; Faculty of Science and University Museum, Kyoto University; and Gene Research Center and Faculty of Education, Shinshu University, for continuous support of our laboratory experiments. 


\section{Literature Cited}

Avise, J. 1994. Molecular markers, natural history, and evolution. Chapman and Hall, New York.

Bermingham, E., S. S. McCafferty, and A. P. Martin. 1997. Fish biogeography and molecular clocks: Perspectives from the Panamanian Isthmus. Pages 113-128 in T. D. Kocher and C. A. Stepien, eds. Molecular systematics of fishes. Academic Press, San Diego, California.

Brandley, M. C., A. Schmitz, and T. W. Reeder. 2005. Partitioned Bayesian analyses, partition choice, and the phylogenetic relationships of scincid lizards. Syst. Biol. 54:373-390.

Brown, W. M., E. M. Prager, A. Wang, and A. C. Wilson. 1982. Mitochondrial DNA sequence of primates: Tempo and mode of evolution. J. Mol. Evol. 18:225-239.

Felsenstein, J. 1985. Confidence limits on phylogenies: An approach using the bootstrap. Evolution 39:783-791.

Hayashi, Y., and M. Matsui. 1988. Biochemical differentiation in Japanese newts, genus Cynops (Salamandridae). Zool. Sci. (Tokyo) 5:1121-1136.

Hedges, S. B., R. A. Nussbaum, and L. R. Maxson. 1993. Caecilian phylogeny and biogeography inferred from mitochondrial DNA sequences of the $12 \mathrm{~S} \mathrm{rRNA}$ and $16 \mathrm{~S}$ rRNA genes (Amphibia: Gymnophiona). Herpetol. Monogr. 7:64-76.

Hikida, T. 1993. Phylogenetic relationships of the skinks of the genus Eumeces (Scincidae: Reptilia) from East Asia. Jpn. J. Herpetol. 15:1-21.

1996. Lizards of the genus Eumeces. Pages 74-76 in S. Sengoku, T. Hikida, M. Matsui, and K. Nakaya, eds. The encyclopedia of animals in Japan. Vol. 5. Amphibians, reptiles and chondrichthyes. Heibonsha, Tokyo [in Japanese].

- 2002. Natural history of the reptiles. University of Tokyo Press, Tokyo [in Japanese].

Hikida, T., H. Ota, and M. Toyama. 1992. Herpetofauna of an encounter zone of Oriental and Palearctic elements: Amphib- ians and reptiles of the Tokara Group and adjacent islands in the northern Ryukyus, Japan. Biol. Mag. Okinawa (30): 29-43.

Hillis, D. M., and J. J. Bull. 1993. An empirical test of bootstrapping as a method for assessing confidence in phylogenetic analysis. Syst. Biol. 42:182-192.

Honda, M., M. Kobayashi, H.-S. Yong, H. Ota, and T. Hikida. 1999a. Taxonomic re-evaluation of the status of Draco cornutus Günther, 1864 (Reptilia: Agamidae). Amphib.-Reptilia 20:195-210.

Honda, M., H. Ota, G. Khöler, I. Ineich, L. Chiro, and T. Hikida. 2003. Molecular phylogeography of the subfamily Lygosominae (Reptilia: Scincidae), with special reference to the origin of the New World taxa. Genes Genet. Syst. 73:71-80.

Honda, M., H. Ota, M. Kobayashi, J. Nabhitabhata, H.-S. Yong, and T. Hikida. 19996. Phylogenetic relationships of the flying lizards, genus Draco (Reptilia, Agamidae). Zool. Sci. (Tokyo) 16:535-549.

- 2000. Phylogenetic relationships, character evolution and biogeography of the subfamily Lygosominae (Reptilia: Scincidae) inferred from mitochondrial DNA sequences. Mol. Phylogenet. Evol. 15:452-461.

Honda, M., H. Ota, R. W. Murphy, and T. Hikida. 2006. Phylogeny and biogeography of water skinks of the genus Tropidophorus (Reptilia: Scincidae): A molecular approach. Zool. Scr. 35:85-95.

Honda, M., Y. Yasukawa, R. Hirayama, and H. Ota. 2002a. Phylogenetic relationships of the Asian box turtles of the genus Cuora sensu lato (Reptilia: Bataguridae) inferred from mitochondrial DNA sequences. Zool. Sci. (Tokyo) 19:1305-1312.

Honda, M., Y. Yasukawa, and H. Ota. $2002 b$. Phylogeny of the Eurasian freshwater turtles of the genus Mauremys Gray, 1869 (Testudines), with special reference to the close affinity of $M$. japonica with Chinemys reevesii. J. Zool. Syst. Evol. Res. 40:195200.

Huelsenbeck, P., and B. Rannala. 2004. Frequentist properties of Bayesian posterior probabilities of phylogenetic trees under 
simple and complex substitution models. Syst. Biol. 53:904-913.

Kato, J., H. Ota, and T. Hikida. 1994. Biochemical systematics of the latiscutatus species-group of the genus Eumeces (Scincidae: Reptilia) from East Asian islands. Biochem. Syst. Ecol. 22:491-500.

Kato, Y. 1989. Watase's line in the light of geology. Nat. Hist. Jpn. 3:14-18 [in Japanese].

Kimura, M. 1980. A simple method for estimating evolutionary rate of base substitutions through comparative studies of nucleotide sequences. J. Mol. Evol. 16:116120.

Kizaki, K., and I. Oshiro. 1977. Paleogeography of the Ryukyu Islands. Mar. Sci. Mon. 9:542-549 [in Japanese with English summary].

1980. The origin of the Ryukyu Islands. Pages 8-37 in K. Kizaki, ed. Natural history of Ryukyu. Tukijishoten, Tokyo [in Japanese].

Kocher, T. D., W. K. Thomas, A. Meyer, S. V. Edwards, S. Pääbo, F. X. Villablanca, and A. C. Wilson. 1989. Dynamics of mitochondrial DNA evolution in animals: Amplification and sequencing of conserved primers. Proc. Natl. Acad. Sci. U.S.A. 86:6196-6200.

Kumazawa, Y., and M. Nishida. 2000. Molecular phylogeny of osteoglossoids: A new model for Gondwanian origin and plate tectonic transportation of the Asian arowana. Mol. Biol. Evol. 17:1869-1878.

Leaché, A. D., and J. A. McGuire. 2006. Phylogenetic relationships of horned lizards (Phrynosoma) based on nuclear and mitochondrial data: Evidence for a misleading mitochondrial gene tree. Mol. Phylogenet. Evol. 39:628-644.

Macey, J. R., J. A. Schulte II, A. Larson, Z. Fang, Y. Wang, B. S. Tuniyev, and T. J. Papenfuss. 1998. Phylogenetic relationships of toads in the Bufo bufo species group from the eastern escarpment of the Tibetan Plateau: A case of vicariance and dispersal. Mol. Phylogenet. Evol. 9:80-87.

Macey, J. R., Y. Wang, N. B. Ananjeva, A. Larson, and T. J. Papenfuss. 1999. Vicariant patterns of fragmentation among gek- konid lizards of the genus Teratoscincus produced by the Indian collision: A molecular phylogenetic perspective and an area cladogram for central Asia. Mol. Phylogenet. Evol. 12:320-332.

Motokawa, J., and T. Hikida. 2003. Genetic variation and differentiation in the Japanese five-lined skink, Eumeces latiscutatus (Reptile: Squamata). Zool. Sci. (Tokyo) 20:97-106.

Motokawa, J., M. Toyama, and T. Hikida. 2001. Genetic relationships of a morphologically unique population of the genus Eumeces (Scincidae: Squamata) from Iotorishima Island, Ryukyu Archipelago, as revealed by allozyme data. Curr. Herpetol. 20:69-76.

Nishioka, M., M. Sumida, S. Ohta, and H. Suzuki. 1987. Speciation of three allied genera, Buergeria, Rhacophorus and Polypedates, elucidated by the method of electrophoretic analyses. Sci. Rep. Lab. Amphib. Biol. Hiroshima Univ. 9:53-96.

Okamoto, T., J. Motokawa, M. Toda, and T. Hikida. 2006. Parapatric distribution of the lizards Plestiodon (formerly Eumeces) latiscutatus and P. japonicus (Reptilia: Scincidae) around the Izu Peninsula, central Japan, and its biogeographic implications. Zool. Sci. (Tokyo) 23:419-425.

Ota, H. 1998. Geographic patterns of endemism and speciation in amphibians and reptiles of the Ryukyu Archipelago, Japan, with special reference to their paleogeographical implications. Res. Popul. Ecol. (Kyoto) 40:189-204.

. 2000. The current geographic faunal pattern of the reptiles and amphibians of the Ryukyu Archipelago and adjacent islands. Tropics 10:51-62.

- 2003. Eumeces marginatus. Pages 102-103 in Nat. Conserv. Div., Dept. Environ. Citizens, Kagoshima Pref., ed. Threatened wildlife in Kagoshima, Animals, Kagoshima Red Data Book. Fund. Environ. Res. Serv., Kagoshima Pref., Kagoshima [in Japanese].

Ota, H., M. Honda, S.-L. Chen, T. Hikida, S. Panha, H.-S. Oh, and M. Matsui. 2002. Phylogenetic relationships, taxonomy, character evolution, and biogeogra- 
phy of the lacertid lizards of the genus Takydromus (Reptilia: Squamata): A molecular perspective. Biol. J. Linn. Soc. 76:493-509.

Ota, H., H. Miyaguni, and T. Hikida. 1999. Geographic variation in the endemic skink, Ateuchosaurus pellopleurus from the Ryukyu Archipelago, Japan. J. Herpetol. 33:106118.

Ota, H., M. Toyama, Y. Chigira, and T. Hikida. 1994. Systematics, biogeography and conservation of the herpetofauna of the Tokara Group, Ryukyu Archipelago: New data and review of recent publications. WWF Japan Sci. Rep. 2:163-177.

Posada, D., and K. A. Crandall. 1998. Modeltest: Testing the model of DNA substitution. Bioinformatics 14:817-818.

Reeder, T. W. 1995. Phylogenetic relationships among phrynosomatid lizards as inferred from mitochondrial ribosomal DNA sequences: Substitutional bias and information content of transitions relative to transversions. Mol. Phylogenet. Evol. $4: 203-222$.

- 2003. A phylogeny of the Australian Sphenomorphus group (Scincidae: Squamata) and the phylogenetic placement of the crocodile skinks (Tribolonotus): Bayesian approaches to assessing congruence and obtaining confidence in maximum likelihood inferred relationships. Mol. Phylogenet. Evol. 27:384-397.

Ronquist, F., and J. P. Huelsenbeck. 2003. MrBayes 3: Bayesian phylogenetic inference under mixed models. Bioinformatics 19:1572-1574.

Saitou, N., and M. Nei. 1987. The neighborjoining method: A new method for reconstructing phylogenetic trees. Mol. Biol. Evol. 4:406-425.

Schulte, J. A., II, J. R. Macey, and R. E. Espinoza. 2000. Phylogenetic relationships in the iguanid lizard genus Liolaemus: Multiple origins of viviparous reproduction and evidence for recurring Andean vicariance and dispersal. Biol. J. Linn. Soc. 69:75102.

Schulte, J. A., II, J. Melville, and A. Larson. 2003. Molecular phylogenetic evidence for ancient divergence of lizard taxa on ei- ther side of Wallace's Line. Proc. R. Soc. Lond. B Biol. 270:597-603.

Sites, J. W., Jr., J. W. Bickham, B. A. Pytel, I. F. Greenbaum, and B. A. Bates. 1984. Biochemical characters and the reconstruction of turtle phylogenies: Relationships among batagurine genera. Syst. Zool. 33:137-158.

Smith, H. M. 2005. Plestiodon: A replacement name for most members of the genus $\mathrm{Eu}$ meces in North America. J. Kans. Herpetol. (14): $15-16$.

Spinks, P. Q., H. B. Shaffer, J. B. Iverson, and W. P. McCord. 2004. Phylogenetic hypotheses for the turtle family Geoemydidae. Mol. Phylogenet. Evol. 32:164-182.

Swofford, D. L. 1998. Paup*: Phylogenetic analysis using parsimony (*and other methods). Ver. 4. Computer software and manual. Sinauer Associates, Sunderland, Massachusetts.

Thompson, J. D., D. G. Higgins, and T. J. Gibson. 1994. Clustal W: Improving the sensitivity of progressive multiple sequence alignment through sequence weighting, position specific gap penalties and weight matrix choice. Nucleic Acids Res. 22:4673-4680.

Toda, M., T. Hikida, and H. Ota. 1997. Genetic variation among insular populations of Gekko hokouensis (Reptilia: Squamata) around a border of the Oriental and $\mathrm{Pa}$ learctic zoogeographical regions in the northern Ryukyus, Japan. Zool. Sci. (Tokyo) 14:859-867.

. 2001. Discovery of sympatric cryptic species within Gekko hokouensis (Gekkonidae: Squamata) from the Okinawa Islands, Japan, by use of allozyme data. Zool. Scr. 30:1-11.

Toyama, M. 1989. Distribution of the genus Eumeces (Scincidae: Lacertilia) in the Ryukyu Archipelago. Page 262-267 in M. Matsui, T. Hikida, and R. C. Goris, eds. Current herpetology in East Asia. Herpetological Society of Japan, Kyoto.

Weisrock, D. W., J. R. Macey, I. H. Ugurtas, A. Larson, and T. J. Papenfuss. 2001. Molecular phylogenetics and historical biogeography among salamandrids of the 'true' salamander clade: Rapid branching of nu- 
merous highly divergent lineages in $\mathrm{Mer}$ tensiella luschani associated with the rise of Anatolia. Mol. Phylogenet. Evol. 18:434448.

Wilgenbusch, J. C., D. L. Warren, and D. L. Swofford. 2004. AWTY: A system for graphical exploration of MCMC convergence in Bayesian phylogenetic inference. http://ceb.csit.fsu.edu/awty.

Wilson, A. C., L. C. Cann, S. M. Carr, M. George, U. B. Gyllensten, K. M. HelmBychowski, R. G. Higuchi, S. R. Palumbi, E. M. Prager, R. D. Sage, and M. Stoneking. 1985. Mitochondrial DNA and two perspectives on evolutionary genetics. Biol. J. Linn. Soc. 26:375-400.

\section{Appendix}

\section{Voucher Specimens}

Specimens and tissues used in this study were deposited in the Zoological Collection of the Kyoto University Museum (KUz). Materials already cited in Honda et al. (2000) and Okamoto et al. (2006) are omitted.

Plestiodon japonicus: Kagoshima City, Japan, KUZ R46918. P. mariginatus oshimensis: Nakanoshima, Tokara Group, Japan, kUz R49298; Kodakarajima, Tokara Group, Japan, kUz R50595; Takarajima, Tokara Group, Japan, KUZ R50600; Amamioshima, Amami Group, Japan, kUZ R50460; Okinoerabujima, Amami Group, Japan, kUZ R36192. P. m. mariginatus: Yona, Okinawajima (\#1), Okinawa Group, Japan, kUz R45922; Ie, Okinawajima (\#2), Okinawa Group, Japan, kUz R62298; Tokashikijima, Okinawa Group, Japan, kuz R62301; Kumejima, Okinawa Group, Japan, Kuz R62303. P. stimpsonii: Iriomotejima, Yaeyama Group, Japan, an uncataloged tissue sample kept in kuz. P. kishinouyei: Iriomotejima, Yaeyama Group, Japan, an uncataloged tissue sample kept in kUz. P. elegans: Taipei, Taiwan, kUz R36205. P. chinensis: Taiton (or Taitung), Taiwan, kUz R60637. 